\title{
The Use of Participatory and Non-Experimental Research Methods in Behavior Analysis
}
O uso de métodos de pesquisa participativos e não experimentais na análise do comportamento
El uso de métodos de investigación participativos y no experimentales en el análisis del comportamiento

\section{Bernard Guerin ${ }^{1}$}

\begin{abstract}
This paper seeks to enlarge the range of research methods in behavior analysis to deal with situations in which even small- or single-sample experimental methods are not possible or not appropriate. This is common for most research with humans, and especially with behaviors under the rubric of social, cultural and verbal. After presenting arguments for this, the paper outlines three methods for describing the everyday, complex structuring of functional relations. The most important of these methods adapts engaged, participatory methods from other social sciences but puts the focus on finding functional relations between behaviors and their complex outcomes rather than just labelling the hidden functional relations as static social 'structures'. Examples of these three methods are given from research on functional analyses of mental health behaviors.
\end{abstract}

Keywords: human behavior; social behavior; cultural behavior; research methodology; participatory research; mental health; functional analysis; social structures 
Resumo: O presente artigo busca ampliar a gama de métodos de pesquisa em análise do comportamento para lidar com situações em que métodos experimentais de amostra reduzida ou de sujeito único não são possíveis ou não são apropriados. Tais situações são comuns para a maioria das pesquisas com seres humanos, em especial quando lidamos com comportamentos sob a rubrica de social, cultural ou verbal. Após apresentar os argumentos que sustentam tal posição, $\mathrm{o}$ artigo explicita três métodos para descrever a cotidiana estruturação complexa de relações funcionais. O mais importante desses métodos adapta abordagens engajadas e participativas de outras ciências sociais, mas coloca o foco em encontrar relações funcionais entre comportamentos e seus produtos complexos em vez de apenas rotular as relações sociais funcionais ocultas como "estruturas" sociais estáticas. Foram dados exemplos desses três métodos a partir de pesquisas sobre análises funcionais de comportamentos em saúde mental.

Palavras-chave: comportamento humano; comportamento social; comportamento cultural; metodologia de pesquisa; pesquisa participativa; saúde mental; análise funcional; estruturas sociais

Resumen: El presente artículo busca ampliar la gama de métodos de investigación en el análisis del comportamiento para tratar situaciones en las que no es posible o no son apropiados métodos experimentales de muestra reducida o de sujeto único. Tales situaciones son comunes a la mayoría de las investigaciones humanas, especialmente cuando se trata de comportamientos bajo la rúbrica social, cultural o verbal. Después de presentar los argumentos que apoyan esta posición, el artículo explica tres métodos para describir la cotidiana compleja estructuración de las relaciones funcionales. El más importante de estos métodos adapta enfoques comprometidos y participativos de otras ciencias sociales, pero se enfoca en encontrar relaciones funcionales entre los comportamientos y sus productos complejos en lugar de solo etiquetar las relaciones sociales funcionales que están ocultas como "estructuras" sociales estáticas. Se han dado ejemplos de estos tres métodos a partir de investigaciones sobre análisis funcionales de comportamientos en salud mental.

Palabras-clave: comportamiento humano; comportamiento social; comportamiento cultural; metodología de la investigación; investigación participativa; salud mental; análisis funcional; estructuras sociales 
Since its inception in animal research, behavior analysis has favored experimental methods (Skinner, 1938). Controversy has sometimes arisen between psychology and behavior analysis since the latter favored small- or single-sample experimental methods (Sidman, 1960) whereas most of psychology has favored large samples and statistical analysis, but the emphasis on experimental methods has been continuous in both.

This paper does not dispute the usefulness of experimental designs in some research contexts, but seeks to enlarge the range of research methods used in behavior analysis to deal with situations in which even small- or single-sample experimental methods are not possible or not appropriate. This is especially important for real life social, cultural and community behaviors of humans, where the functional relations are complex and often hidden, and where there can be ethical issues for doing experimental research designs. This paper seeks to do this while keeping strictly within the basic principles of functional behavior analysis, arguing that the use of experimental methods has never been a necessary principle of behavior analysis.

For difficult or complex research situations, this paper will advocate switching from analyzing simplistic functional relations directly through experimenting (reversal designs, etc.) to describing the everyday structuring of functional relations and then doing idiosyncratic interventions. This paper only advocates such a switch in difficult research situations which will be described below, although this includes a large part of understanding human behavior once social, discursive and cultural practices are included. Some examples of three research methodologies for doing this will be given and illustrated with examples from research.

\section{What are the goals of research?}

Part of the argument here goes back to the goals of doing research in the first place and the assumptions made. Traditionally in psychology, to understand people the metaphor has been to 'get into their minds. We must do research to understand what is going on in a person's mind, mental processes, or internal cognitive processes. In this way, we will be able to predict what people will do. Notice now that if you agree with such a view then the following methodologies are acceptable if you want to understand a person's behavior: (1) analyzing social behavior in labs or in front of a computer; (2) doing psychotherapy by just talking with a person in an office for 50 mins; and (3) understanding people by just giving them questionnaires to fill out, even online so you do not even meet them. If the key to understanding people is 'in their mind' then these methods are perfectly acceptable. We can capture 'their internal minds' without even needing to interact with them. They can simply tell us what is 'on their minds' in a questionnaire or in an interview, even about social and cultural topics. You can, of course, do these three with other better assumptions and limitations as well, especially 2 .

Another assumption about research which is frequently made is that in order to predict and understand complex behavior we first need to do research on basic or foundational units, and then build 'up' from these to complex behaviors. This derives from the 'Method' of Descartes and is part of both the behavior analysis and psychology traditions. For the former, we study simple functional contingency relations in a controlled laboratory setting and treat these as foundational or basic units. The assumption is that these foundations will eventually allow us to build up a way to understand and control more complex behaviors.

There is no good reason why this assumption must be true, however. Ironically, this is more a problem for behavior analysis than general psychology, because for behavior analysis the environment is a strong determinant of behavior and so the idea of finding basic or foundational events independently of any specific setting or context goes against behavior analysis principles in this way. The environmental or interactional foundations of behavior analysis would suggest that we might not find any foundational contingency relations which are independent of their specific environments.

This means that the animal experimental setting (Skinner, 1938) itself might play a greater role in producing the 'common' specific contingency relations typically found (FI, VI, etc.) in denuded environments than thus far acknowledged, although I will not go further into this here. The same point 
has been directed at psychology by Gibson (1979), among others: that experimental settings remove most of the context and if your principles are that the environment or context plays a major role in shaping behavior (as Gibson argued for perception), then you have removed all the relevant ways of understanding the behavior in that experimental setting.

Clearly, behavior analysis principles are that the environment or context plays a major role in determining behavior. If we look at the basic experimental situations in behavior analysis, however, the goal is to obtain:

- A barren environment with no context except that introduced by the experimenter

- A single physical response (more or less)

- A single consequence (more or less)

- Little or no relevant history context for the organism (usually)

- No distractions or alternative contingencies

- Functional contingency relations in place which the researcher has programmed (structured) and knows in advance

- Deprivation levels also programmed and known by the researcher

For a discipline which advocates for a strong role of the organism's environment, it is not clear how useful this research strategy is in terms of eventually explaining complex behaviors by humans or 'building them up' from 'basic units' found in such denuded environments. Indeed, Skinner himself approached the more complex human social, linguistic and political behaviors only conceptually, and did no experimentation or systematic research.

As a metaphor to help think these arguments through, I like to compare the experimental analyses of functional relations, as studied in JEAB, JABA and elsewhere, with molecular relations in chemistry. We know the molecular structure of wood (cellulose), and chemists and biochemists can make some use of this basic or foundational knowledge. However, if you are working as a carpenter, knowing the molecular structure of cellulose is very rarely useful and might even inhibit what you attempt to do. When working as a carpenter, real wood is too large for molecular analysis, is impure, has a history of growth which is never the same for two bits of the same wood (even though they still have the same molecular structure), and has other substances mixed in with it. These complexities actually provide features that make carpentry or sculpting of wood interesting (such as knots, grains, or impure growths). In terms of what I will say later, carpenters learn the contingences of real wood by participating and experiencing the quirks of shaping wood into other forms (like participatory research).

When chemists experiment on the molecular structure of wood, however, their methods have all the same features of any experimental method: they remove the context, remove the impurities, and remove the historical idiosyncrasies of any piece of wood they use. So, in the end, the very basic or foundational analyses of wood might be true but they are rarely helpful to a carpenter dealing with complex, real wood. This does not undermine what is found by the molecular chemists, however, and their work should not stop. My point is only about whether attempting to look for fundamental units first, by researching in denuded environments, will necessarily be a useful methodology for analyzing complex behaviors and real wood in the long-run, and whether we should even attempt to use (or mimic) the experimental methods (and findings, Skinner, 1953, 1957) when dealing with complex behavior analyses.

To give an example of this last point directly from behavior analysis, Guerin (1994) reviewed all the extant literature on analyzing social behavior which was conducted with some form of behavioral perspective. Overall, the results from this literature were disappointing. Among all the studies, there were: (1) too many which only focused on experimental research and ignored all other important findings from descriptive social science research; (2) too many only analyzed those social behaviors in which the situation looked like or resembled an experimental animal setting; (3) too many were only doing research on human social behavior by creating situations just to 
look like or resemble an experimental animal setting; (4) and too many were overlaying new ('reinforcing') events on existing functional life patterns as if these were simple experimental settings, and with no thought as to how these might interfere with other structured patterns already in the person's lives. All the rich social science research sources which have described what real contingent relations are structured into people's worlds, contexts or environments were typically ignored.

But if the functional outcomes shaping people's behaviors are already out there and structured into the person's environment and world, and not 'in their mind', then as researchers we perhaps need to 'get out into their worlds' to describe what is functional and shaping people's behaviors.

\section{When are small- or single-sample experimental methods difficult or impossible to use?}

Before going on to outline some non-experimental methods we might use to describe the functional relations which are already structured into people's worlds, we need to be careful about when to use such alternative methods, to prevent throwing babies out with bathwater. I certainly do not advocate returning blindly back to the methods of traditional psychology or stopping experimental methods when they are useful and do not overgeneralize their conclusions. But we sometimes need to change the approach from, control every part of the context except a single functional relation and see what happens to behavior, into a different approach, how can we systematically describe the functional consequences which are already structured into people's environments, and then try and change those structures in the idiosyncratic environments being studied. While some applied behavior analysis work in already contingency-rich settings with experimental methods, we still do not find out whether the 'experimental' function added to the situation works or does not work because of the already existent contingencies. This means the new function added might not work in the original situation. The following are some settings in which non-experimental methods might be required:
Complex events. This includes a large part of human behavior, and especially those parts we call social, cultural or verbal. The complexities might be from multiple behaviors operating simultaneously, multiple settings having a simultaneous influence, or multiple functional consequences having a simultaneous effect. It can also be from multiple persons operating on each other at the same time. It is also the case that adult humans can and do comment on and talk about any other functional relations in their world, which means human events are almost always socially complex no matter how simple they superficially look. Given this ubiquity of social and verbal contingencies in any and all human behavior, simple, basic units such as threeterm contingencies are never likely to be found except conceptually (Skinner, 1953). While Skinner (1957) applied the simple contingency analyses to verbal behavior this was never a full analysis and relied on the topography of what was said and had little comment on the outcomes except to posit "generalized social reinforcement' from language communities as the sole source of talk. No research was done on this even though there is a plethora of research available elsewhere (Guerin, 1997).

Exploratory research. If behavior in a novel realworld setting is of interest then non-experimental methods might be appropriate since we will not know before commencing what controlling functional contingencies might even be present at all. In animal research this is not required because the researcher sets up the functional contingencies, but in real world human research we usually need to find this out first. If this is not done then there is a risk that guessing based upon 'common sense' theories and biases will be used to 'find' experimental variables.

Settings of highly diverse or variable behaviors, contexts or functional relations. In settings such as therapy, social behavior or community research, any part of the contingencies might be highly idiosyncratic to single people or groups, and so experimental control of other variables will be nearly impossible. In such situations, we do not know the contingent relations in the environments and so any trying to 'exert experimental control' will be purely 
guesswork. The usual approach is to add or overlay novel events "reinforcers" in such situations but we then have no idea how these will interact in the original contexts. Probably all human behavior will have been shaped by hidden societal structures of at least: social relationships, patriarchy, economics, cultural practices, opportunities, colonization, and history (Guerin, 2016). The aim of other research methods - the point of this paper-must therefore be to describe the functional relations which are already structured into the persons' environments, and observe in situ how these contingencies work and interact.

So, while the methods to be described below might have similarities to other methods used in the social sciences, they are specifically aimed at describing, analyzing and changing functional relations rather than just describing 'structural' variables without the necessary functional analysis between the environment and the human actions. This is how they differ from social anthropology and sociologythey use their methods but build in the behavior analysis search for functional relations.

\section{Some non-experimental methods for researching functional relations in complex settings}

It has been argued that extra methodologies are needed to describe the structure of the functional contexts of people's real lives. They are not as 'exact' as experimental methods but I have argued implicitly that this 'exactness' is illusionary when dealing with complex situations.

I will briefly describe three methods which I have found useful. It must be remembered that by definition these are not perfect methods that will always lead to correct functional analyses. Like any behavioral analysis (Sidman, 1960; Skinner, 1938), only by engaging directly and changing the environment and then seeing what happens will we know the functional relations with some certainty, although if there is high variability then there is no guarantee that the functional relations found will remain the same over time or between different people anyway. In this sense, the 'classic' functional relations of stable VI, VR, FI and FR are probably artefacts of the animal experimental procedures which will never be found in those forms in real life, even for animal behavior. Once again, this is not an argument to stop the basic research but to recognize its limits in complex situations and find ways to move beyond mimicking such methods with real life.

\section{Method 1. 'Possibility training'}

Elsewhere I have suggested some guidelines for what I called 'possibility training' (Guerin, 2016, pp. 18-23; cf. Goldiamond's 'alternative sets', 1975). This simply means that with training, experience and practice, researchers can brainstorm many possible functional relations in a given setting. Possibility training is not strictly research but a preamble to research in complex settings, which aims to sensitize researchers to real world functional relations. Practical rules suggested for this are to:

- avoid fixating on only one or two possibilities and only ones that seem obvious

- avoid fixating only on possibilities that match common knowledge or everyday understanding

- avoid guessing without more details of the context

- avoid interpreting the social behavior in terms of an idea, notion or theory for which there is nothing observable in the context or even potentially observable

- be cautious about incorporating what is not present or not visible as possibilities without some observations to back this up

- use contradictory or complex possibilities and do not simplify until you have some observations

- do not suspend your own personal experiences but suspend thinking that they are exclusive or complete explanations

- try to think of the opposite or contradictory possibility to the obvious one 
- try to find at least three very different possibilities

- filter through each of five contexts: social, cultural, environmental (opportunities), economic, and historical

- be both critical and creative simultaneously

- have a strong but critical focus on observations that have been made

- learn from those who have experience and a focus on observations

Once again, these are not aimed at suggesting causes, factors, or theoretical variables, but at suggesting possible functional relations which might be occurring in the setting with the particular people involved. As follows from Method 3 below, those researchers with the most experience of the behaviors, settings and functional outcomes will be in a better position to do this. Although experience is no guarantee, I generally trust practitioners who engage with people over theorists and conceptual writers.

An example of functional possibilities with verbal behavior. In Skinner (1957, p. 36), a well-known example was given of some verbal behavior (probably at dinner), "Pass the salt!" There was no research given around this and no descriptions of the contexts or outcomes. Mainly for reasons of presentation, Skinner only gave one single possibility for a functional analysis and called this a 'mand' ('manding' is a better way to describe the functioning). Thus, it was assumed in the example that the person asking for the salt wanted or needed the salt (salt was said to be the 'ultimate reinforcement' of previous similar episodes). Like the experimental animal chamber, he conceptually assumed only one set of 'pre-programmed' contingencies.

However, for any real-world occurrence of this behavior, "Pass the salt!", there could be many functional possibilities arising from more complex, hidden, unknown or diverse contingent relations. Most of these have nothing to do with salt deprivation, and most are about regulating everyday social relationships rather than about regulating food (cf.
Guerin, 1992, for food as a social relation rather than a hunger relation). This is more in line with what a discourse analysis would generate when the full social context is properly investigated. Some possibilities of functional settings for this comment, "Pass the salt!" might be:

- You want/need the salt because deprived (the original possibility)

- You want to stop the person with the salt from looking at what is happening behind them (a distraction)

- Showing off your culinary tastes

- A family joke about something the Dad did once

- A rude joke involving slang (I will not elaborate)

- A conversation opener (called 'fishing' by sociolinguists, Pomerantz, 1980)

- Avoiding silence

- A way to stop people using their phones at the table

- A reminder that someone needs to buy more salt at the shops

\section{- A Game of Thrones reference}

The point is not that any one of these will necessarily be true but that we need ways to find out which of these is functional in any idiosyncratic context. And this raises the methodology question of: how do you actually find out which of these occur in real situations, instead of doing armchair analysis? In pursuing this, I have found discourse analysis and sociolinguistics much more useful than the category system of Skinner (1957) since it encompasses many more possibilities of what is functional in real life contexts (Guerin, 1997, $2003,2016)$. Both discourse analysis and some of sociolinguistics is based on, or can be based on, 
finding functional contingent relations since the entire context for such speech is described. They are included in Method 3 below.

\section{Method 2. 'Backwards engineering' of functional relations from real observed behaviors}

In this method for analyzing functional relations in complex human behavior, many real and diverse examples of the behaviors being investigated are collected along with as much descriptive details of the setting and the possible consequences or effects of the behaviors involved (the consequences will not be simple or immediate, it should be added). In a similar way to possibility training, this does backwards possibility brainstorming to suggest what functional relations might have been operating to produce these described complex behaviors. That is, from what situations (contexts and functional outcomes) could these observed behaviors have been shaped (cf. Baia, Neves, Almeida Filho, de Melo Junior, Souza \& Lemes, 2017)?

Once again, coming up with the backwards engineering of possible functional contingencies which might have shaped the actual behaviors observed is no guarantee that any of them will be true-only engaging with and changing the environment will do that (Sidman, 1960). And again, as before, the exercise is directed not at backwards engineering for 'causes' of the behaviors, but backwards engineering for possible settings and functional outcomes which might have shaped the behaviors that we know occurred.

An example of backwards engineering of possible functional relations. As an example of backwards engineering, I will briefly look at a functional analysis of domestic violence and how it might arise (Guerin \& Ortolan, 2017). For backwards engineering, the first step is to gather descriptions of the behaviors with details, if possible, of the contexts and outcomes. In this case, there were lists and descriptions available of real male perpetrators' behaviors with a little context. Several broad categories of behaviors commonly used by abusive men were used: economic abuse, coercion and threats, intimidation, emotional abuse, isolation, minimizing, denying and blaming, children, and male privilege. These had subgroupings of more specific behaviors within those categories.
With this start, we then suggested possible functional outcomes of these male behaviors for controlling the females' behaviors, which were missing from these descriptive lists. For example, one subcategory of 'economic abuse', had outcomes of: preventing the woman from getting her own economic resources; placing the woman in a context (the home) in which she is more easily monitored and controlled by the man; and preventing her from making independent social contacts. From this we could group similar functions, and, in our version, we grouped the behaviors and outcomes under five broad functional categories: direct actions; manipulating contexts or setting events for actions; strategies of secrecy; strategies of monitoring; and verbal construction strategies. The material is there for other possible groupings.

These five broader functions of the males' behaviors are important because they show, in general, "What are the males are after?" Men operate these functions in many diverse ways, too many to teach women to recognize. However, if we could now teach women to recognize just these five functions of the diverse behavior of the men, we might have a more useful intervention approach. So, by backwards engineering the possible functions of the male perpetrators' diverse behaviors, we can then do idiosyncratic interventions with individual women to see how and when these functions appear in their specific domestic relationships.

As for Method 1 above, none of this is meant as a grand theory or proof of domestic violence functional relations. Any suggestions must be checked in situ and new possibilities might emerge then. These are also useful, however, to sensitize researchers and practitioners to all functional possibilities rather than the purely structural approaches used in most research, and this should lead to better observational research and better 'idiosyncratic interventions'.

\section{Method 3. Embedded and intensive research methods ("get out into people's world")}

It was argued earlier that if the functional contingencies shaping and maintaining human behaviors are already there in people's worlds then researchers need to go out into those worlds and systematically describe how these functional relations are struc- 
tured, how they operate, and how changes occur in the structures (and hence in behaviors) over time (or even actively change these with ethical approval). If there are recurring functional relations then these will appear in research as 'structures', but we know that changing contexts will change the structuring. Most social science research has been aimed at describing 'structures' built into our worlds and predicting behaviors from these alone, but this will only work if the functioning is stable-structures can be changed by changing the outcomes, as we know in behavior analysis.

Possibility training assumed that researchers had read thoroughly about the behaviors in question or had some experience with these behaviors, in order to come up with possible functional outcomes which might be operating. Backwards engineering assumed that researchers had already existing lists or descriptions of the behaviors in a context to use for their analyses. The third set of methodologies are about going out into a person's world to describe the behaviors and the functional outcomes shaping those behaviors, preferably using Methods 1 and 2 both before and after (cf. de Carvalho, Sandaker \& Ree, 2017).

To do this we can learn from social anthropologists and some sociologists who have long gone 'into the field' and described all the multiple contexts which they found occurring. They have not usually focused on linking the observed contexts with functional outcomes of the behaviors, however, and this is what behavior analysis can add to improve such research. Typical 'analyses' from social anthropology and sociology suggest that the behaviors result from 'social structures', but without showing the functional basis of these patterns or structures-class structures, racial structures, economic structures, social structures, family structures, personality structures, social norms, hereditary structures, cultural structures, etc. To say it again, finding structures means that there are repeated functions which are not changing quickly.

That is, most social science research seems to document 'permanent' structures in social and societal groups which seem to predict behavior. However, these structures are based on repetitive functional outcomes, and they need not be permanent in any society and they certainly need not be necessary for any individuals within that society (we all break the structures of 'social norms' from time to time). But the structural approaches can predict behaviors in the short term, especially with large combined data sets for many individuals, but even then, such structural predictions only work if the environmental outcomes remain in place and are repetitive. The functionality inherent in any of the 'structures' which are found, therefore, needs more work on the part of researchers, to show how these structures come about. Much of real life escapes these social and societal 'structures' but this is lost in aggregate data and when structures are nominalized.

There have been a few functional approaches by social anthropologists but they have been extremely simplistic reductions just to obvious 'material' outcomes (typically food) and lost all the complexities of the actual functional relations (e.g., Harris, 1979; Rappaport, 1984). In modern western society, for example, most functional contingencies will be directly linked to gaining money and access to social networks rather than to food directly as an outcome (Guerin, 1992, 2016).

My suggestion, therefore, is for behavior analysts to adapt these social science participatory methods by re-focusing on describing (1) the contexts, (2) the behaviors, and (3) the common outcomes of those behaviors, so we can get a better version which behavior analysis can use in complex situations. There are many advantages for this functional approach. Doing these methods improves the brainstorming of both possibilities and backwards engineering from known behaviors. Participation in the participants' lives also usually means, in my experience, that the researcher has the same functional contingencies acting upon them in the setting and so that can be described in addition. Finally, participating and observing repeatedly over time means that your analyses can be checked by participants and on future occasions, and that natural or implemented (with ethical participant involvement) changes in the environments can be tracked alongside recording as much as possible about the events taking place (Guerin, Leugi \& Thain, 2018). This gives better evidence for functional relations between behaviors and outcomes by using interventions, even natural ones, alongside collecting 
details of contexts and outcomes (Sidman, 1960). But notice that 1-3 above will not form simple three-term contingencies.

Descriptions of both contexts and functional outcomes by such methods must utilize the findings of all the social sciences, and not just be restricted to previous research within behavior analysis. The descriptions should not be focused on finding schedules of reinforcement which superficially look like FI or VR schedules, but focused on those parts of the complex environments which possibly shape the behaviors observed. As a starting point only (Guerin, 2004, 2016), descriptions over time must include details of resources (outcomes, consequences), social relationships with audiences, groups, and populations, strategies of secrecy, avoidance and monitoring, strategies of language use and other discourses, and all the major broad contexts of human life which shape most of what we do (social relationships, cultural, economic, political, historical, opportunity, patriarchal, colonization). These are common functional structures for humans.

The main features of such 'embedded' or 'intensive' research methods will vary depending upon the research and the setting. Here are some suggestions based on social anthropological research, community psychology research, and my own experiences (Guerin, Leugi \& Thain, 2018):

- Participation where possible. In general, participant observations are best (if there is ethical approval and participant agreement and engagement). This means for the researchers to expose themselves and their observations directly to the functional environments operating by participating in the functional contexts with their participants and not just rely on participants reporting verbally in your office what has occurred in the past. This not only helps verify any reports by participants but also allows those same functional contingencies to operate on the researchers (albeit never in quite the same way as for participants, but this is always true). In this way you can even 'experiment' by going together to new places or events with your participants to see what happens. So, the researcher becomes 'embedded' in the participant's func- tional life for a period and can get a very good contextual view of their life as well as the specific issues being researched.

- Conversational chatting. Rather than using interviews, there is a strong tradition in social anthropology and community psychology for informal chatting or 'yarning'. The research is therefore informal, non-interrogative, conversational, chatty, and 'talking around' the topics (Pe-Pua, 1989), just like a normal conversation with a friend in fact. This has several advantages, including the participants feeling safer and less interrogated, allowing the participants to raise their own ideas and observations (which the researcher might never have thought of otherwise), and fitting in with normal conversational practices and leading to the more relaxed social relationships that go with this.

- Repeated talks. If possible (or else make it possible), always talk and engage with the same people more than once, and many times if ethical. This has numerous advantages, such as the participants being engaged in a stronger social relationship than for normal research, and a more personal involvement to the point of an acquaintanceship or friendship. In fact, in line with Indigenous and feminist research methods, the best outcome is if the participants become partners in the research from the start. Further, with repeat conversations, everything that you as a researcher are observing, concluding, seeing, and thinking about, can be talked through with the participant both as they happen and afterward (a type of validity). And if the participants go off-topic during a conversation, they do not have to be interrupted and brought back 'on task'. Their diversion can be continued and the original thread be picked up in the next meeting. However, most researchers using similar methods find that the 'off-topic' contextual material usually turns out to be useful in ways the researcher does not appreciate at first.

- The participant knows best. It is a good research practice to let the participants tell the stories as much as possible, and let the partici- 
pants take control of the talking if they wish without interruption or re-focusing back onto 'themes' (it is likely that they know something you do not).

\section{Three examples from a functional analysis of mental health behaviors}

Myself and colleagues have now done a number of research studies using these methods to investigate the functional shaping of mental health behaviors. Some use a shorter method (Fromene \& Guerin, 2014; Fromene, Guerin \& Krieg, 2014; Rowe \& Guerin, 2018; Trzepacz, Guerin \& Thomas, 2014), while others have been longer (over 2-8 years on the projects) and engaged with the mental health of people in poverty, remote Indigenous communities, and refugee communities (e. g., Guerin, 2017a, Chapter 8; Guerin, B., \& Guerin, 2012; Guerin, Elmi \& Guerin, 2006). I will give a brief example of one longer and one shorter such research project, followed by another recent example of backwards engineering relevant to mental health.

\section{Example 1. Indigenous community mental health}

To explore the 'mental health' behaviors of remote Indigenous Australians, we engaged with one desert-living community over several years (Guerin, 2017a, Chapter 8; Guerin, B., \& Guerin, 2012). This was in the Anangu Pitjantjatjara Yankunytjatjara (APY) Lands in the far north of South Australia. We first spent $a$ year just visiting the community for a few weeks at a time, and getting to know the people and the contexts, and for them to know us, but without any research being done. This included volunteer work, advising on issues we could help with, helping to start up a second-hand clothes shop in town, and helping people from the APY Lands when they visited Adelaide where the researchers lived. After about year we got approval from the community council to talk to people about the research using our methodology.

The methods did not include interviews, focus groups, questionnaires or experimental control groups. The methods did include some census data (quantitative), a lot of targeted yarning or informal chatting over a long period wherever this was appropriate, more opportunistic yarning or informal chatting wherever appropriate, observations while living in the community, participation in meetings and events, talking to key other people, and testing out ideas and interventions as was natural and appropriate.

The aims were to observe and participate in the functional contexts and relationships, to observe and carefully document the contexts in which behaviors appear and in which the complex social strategies used by the people are shaped, to place the research areas of interest (mental health behaviors) into their functional contexts, and to make repeated observations and document different contexts and what happens, all the while checking with the people themselves what we were documenting and concluding.

So, for 3-4 years we participated on and off in the life of the community, and talked with many other relevant people (medical people, psychiatrists and clinical psychologists, government service workers, other desert communities). We observed and learned about the contexts for all the stresses and conflicts arising, especially those that became labelled as 'mental health' issues by the health services.

What did their 'mental health' look like? If you looked only at the topography of symptoms, and not the functioning, then there were strong resemblances to what is described in the DSM lists. They had similar looking 'mental health' behaviors to any other group (depression behaviors, anxiety behaviors, florid talk and 'delusions' sometimes). However, when we included what we had learned about the functional contexts from which these behaviors arose or were shaped, there was a difference. From what we could discern, their main stressors and conflicts which led to the behaviors that 'looked like' the DSM behaviors (and which were a source of suffering for both the individuals and the whole community), arose from three very different and idiosyncratic functional contexts.

Family and community issues. First, many of the behaviors arose from family and community concerns which led to stress and untenable situations. There were family issues and conflicts between families, but these were very different to those of western 
families living in cities. Living in extended families in a remote community with limited resources led to inevitable conflicts, and the 'mental health' behaviors arising from these potentially bad environments were not always found with the persons most closely connected with whatever the disputes might have been, often someone who seemed tangential was affected (although this could usually be clarified by examining their place in the family structures). Further, many of these conflicts arose just from families trying to keep together in the face of westernization. The second of the family and community issues arose from or were directly shaped by the economic issues of trying to maintain their community in the face of a hostile physical environment and following their loss of traditional land and food sources through colonization. Third, there was a very real stress from not being able to maintain their traditional relationship to their Country (land), which in most cases were now being run as cattle stations 'owned' by whitefellas (cf. a different community, Trzepacz, Guerin \& Thomas, 2014).

These issues of conflict and stress were functionally related in very complex ways and involved the effects of colonization through disruption of traditional practices. That is, the behavior of individuals might have been socially and verbally shaped into certain community practices since birth but the reality of their way of life and community no longer matched this. Therefore, conflicts and stresses arose from contexts which were difficult to observe and more difficult to resolve. But the structuring of those contexts both of learning cultural practices and the effects of colonization on enacting their practices was very real and punishing.

\section{'Bureaucratic Stress Syndrome' or BS syndrome.} The second and third contexts for stress and conflict more directly involved community and government issues, which had hidden functional relations with their 'mental health behaviors'. The first of these we labelled (tongue in cheek) the 'bureaucratic stress syndrome' and involved the huge amount of bureaucratic process needed by all members of the community. That is, the Australian government closely ran all aspect of the community while superficially giving 'governance' to a community council which had little real power.
To get even small things accomplished in these communities, a lot of bureaucratic involvement was necessary, and this could mean driving hundreds of kilometers to government offices just for minor services. This put enormous pressure and anxiety on many of the families and family members in these communities. Unlike living in cities, there was also no choice in most cases of service providers so they had to work through one (controlling) service provider and maintain a relationship with them even if their offices were a long way off. While to those of us in the city the pressure of bureaucracies might seem trivial, this was huge in these communities and they had no power to change anything. Therefore, the bureaucratic governance of the community was a strong shaping context of mental health and illness behaviors.

'Policy Dis-Stress Syndrome'. Related to the above, we also found that the over-arching policies which governed how the communities were allowed to operate were changed constantly by government policy-makers in the far-off Australian capital cities. Many times, we were present in communities when a new policy was faxed from a capital city requiring everyone in the community to change their bank accounts, their method of payments, or how they ran their community store. Such events stressed out people and led to conflicts (again, usually along family lines, which exacerbated the normal family disputes unnecessarily). And once again, the communities had no choice in these matters and little say in the decisions which had been made.

In all, the functional contexts which seemed to lead to the stresses, anxieties and conflicts from which the 'mental health' behaviors arose were very different to what happens elsewhere. We do not believe this is something special or 'Indigenous' but purely a result of the specialized set of environments in which people in these communities are embedded, and have been for many centuries. It is 'cultural' only in the sense that they all learn certain ways of behaving when growing up in these communities, which have been in place for many generations, but which do not work well anymore because of practices which are enforced by government. They cannot be 'explained' by culture, however (Guerin, 2017a). They are explained by the 
conflicting functional consequences of their traditional practices and the effects of new functional consequences imposed by western colonization.

What this does mean is that for interventions with the 'mental health' behaviors or symptoms, we need community interventions in addition to any individual changes (Guerin \& Guerin, 2012). In this sense, community development rather than individual therapies is needed, and the bureaucratic, economic, community and social relationship contexts all need changing if we are to successfully relieve the suffering.

\section{Example 2. Borderline Personality Disorder (BPD) and some Indigenous urban people}

The second example exemplifies a shorter version of Method 3 which we commonly use, with four Indigenous women and one Indigenous man who had been given a BPD diagnoses at some point but were not currently in crisis (Fromene \& Guerin, 2014; Fromene, Guerin \& Krieg, 2014). In this research, the five had repeated conversations over a period but there was little participatory work outside of the research setting. They were talked to and observed at great length, and this was the first research in which we explicitly gave them the DSM 'symptoms' to discuss in terms of their life histories (when did these symptoms first start, what was the original contexts for the symptoms, what were some outcomes of these behaviors, etc.). At that time, we used the nine main "symptoms" for BPD in the DSM-4: frantic efforts to avoid real or imagined abandonment; unstable and intense interpersonal relationships; identity disturbance; impulsivity in at least two areas that are potentially self-damaging; recurrent suicidal behavior, gestures, or threats, or self-mutilating behavior; affective instability due to a marked reactivity of mood; chronic feelings of emptiness; inappropriate, intense anger or difficulty controlling anger; and transient, stress-related paranoid ideation or severe dissociative symptoms.

For this research, we focused on only two main contexts: the historical/cultural contexts which might have shaped the nine symptoms in these specific populations, and the personal history contexts of the five participants, focusing mostly on their social and cultural relationships. The first was done through reviewing historical materials and relevant research, and reviewing a lot of literature on the history of colonization in terms of the "symptoms". The second was through the repeated conversations with participants. The research aimed to suggest ways that the nine behaviors could arise from these historical and personal contexts, looking for "possibilities" of functional relations between their environments and their behavior.

For the historical context, colonization produced many extremely bad environments for Indigenous Australians which were ignored by the government. These were the historical/ cultural environments in which they grew up: the functional relations which were in place in their bad environments. The full results are in the original papers (and Guerin, 2017a, Chapter 8) but a few examples will be given here.

For the first DSM symptom-frantic efforts to avoid real or imagined abandonment-there were numerous features of their environments shaped by colonization which could account for the shaping of these behaviors, and these were also ratified in the conversations. All participants had experience of the government's on-going culture of forced separation from their parents as children, which is called the Stolen Generations in Australia (cf. the Jesuits in Brazil and descimento). Most of the participants had this happen to at least three generations within their families, babies taken from parents and put into care for no reason other than they were Indigenous. These aspects also historically have led to a great loss of community and family structures for Indigenous Australians. Participants reported this also as leading to violence and neglect within families, and a strong mistrust for self and others. The point is that these contexts alone are enough to shape frantic efforts to avoid real or imagined abandonment.

These same conditions were also likely involved in shaping the second BPD symptom-unstable and intense interpersonal relationships. The historical contexts produced by colonization saw a large number of Indigenous children raised in alternative care, unable to form appropriate attachment relationships because they have been neither in a stable form of care nor within their traditional communities. The colonization literature also shows cycles of learned hopelessness, leading to many abusive re- 
lationships which were never present in traditional communities. These all figured in the conversations with the participants as well, who emphasized very bad histories of abuse, neglect, and violence brought about by these conditions, and never allowing them stable relationships even later in life. Most reported being unable to form satisfactory relationships in either the mainstream or Indigenous worlds-they were caught in between.

The results have been giving briefly here, but they suggest that we should be tracing the 'mental health' behaviors-here the symptoms of BPDto the functional environments in which they have been shaped. These environments must include the social relationships, opportunity, cultural, colonization, and historical contexts. In this way, rather than participants having a "Borderline Personality", re-think that they have had "Borderline Socializing Contexts". In this case, these same shaping contexts have been present over several generations and established as 'structures' by colonization and ensuing Australian government policies.

The other conclusion to be drawn from this is that the participants' "borderline" social environments need the interventions, rather than the individuals or their 'minds'. Instead of some therapy, we need to change policies, change government actions, promote Indigenous activism, and change individual therapy into community development activism (Guerin, 2010). But to do those social interventions we need to have described the hidden environments first, and that is what these methods can help achieve.

\section{Example 3. Modernity and mental health: A backwards engineering}

There are many indications that 'mental health' has changed over the last century. For the current ideas about mental health, in which mental health issues arise from brain diseases, this should be quite surprising, since there is no good reason for how brains might have changed. If instead, we assume that behavior is shaped by the outcomes of its many contexts or environments, then this should not be surprising at all, since our human worlds have changed dramatically.

One change we are currently researching is the large rise in both depression and anxiety disorders, especially amongst younger people in western societies, and especially females. Our participatory and conversational research about this issue are still ongoing, but there are a large number of changes in our environments which can be potentially put forward as strong shapers of generalized depression and anxiety. These 'hidden environments' of modernity have been put into behavior analysis terms with possibility training and backwards engineering (Guerin, 2004, 2016, 2017a). The following are just two examples of these, drawn from many areas of social science research (e. g., Braedley, \& Luxton, 2010; Giddens, 1990; Wilkinson \& Pickett, 2010) which we are now following through with participatory research. This is backwards engineering of how modern forms of mental health issues might have arisen functionally from new relationship contingencies in modernity, and from the contingences of capitalism.

Relationship contingencies in modernity. In modern western life, unlike most of human history, our main social relationships are now with strangers, and most of our time is spent with non-kin people. Sociologists refer to these relationships of modernity as 'contractual relations' because money is the most common form of reciprocity maintaining these relationships over time. The point here is that the social properties (functional relations) of strangers, compared to the social properties (functional relations) of families, are hugely different. Here are some of the broad functional relations (contingencies) from working backwards:

- You might never see the strangers in your life again, as they could disappear tomorrow without needing any confirmation from you

- There is little or no obligation to strangers beyond the contractual relationship

- Strangers are not monitorable usually outside of a single 'compartment' in your life

- Strangers in your life generally do not know your family or even your friends, so families have no functional control over the people in your life 
- You therefore have little or no influence through your family or friends over these strangers; to solve conflicts you have to work through other strangers such as Human Resources at work or the police

- Strangers have little or no shared history or familial cultural patterns, they typically know little of your other life contexts

- We have many more contradictions of views and variations between all the strangers we know and long-term family, so conflicts are likely

Contingences of capitalism. Our functional outcomes/resources and the distribution of these outcomes/resources (the structure of contingent functional relations) have hugely changed through capitalism and neoliberalism. So, the contingencies between what we do and the outcomes of what we do (the definition of behavioral analyses) has changed and is very specialized now because of an economic system outside of our control which has become dominant over the last two or three hundred years.

- All resources (outcomes) come through one form (money)

- Most money comes through strangers

- Our relationships with strangers therefore become hugely important in life

- However, our relationships with strangers are very uncertain (see the previous social properties given above) therefore increasing anxiety

- The methods of distribution of resources through capitalism promotes competition between people (even within family)

- The distribution of resources through capitalism promotes bureaucracies and rule-based outcomes which increases uncertainty and anxiety

- All this means a lack of control over outcomes for individuals
Similar methods of backwards engineering of possibilities as above can be used to analyze other modern environments which have changed in the last hundred years: patriarchy, compartmentalization of modern life, structures of inequality, changes in 'culture' patterns and how they function, and colonization effects (Guerin, 2017a). These also blend with each other to create more complex 'functional environments'; for example, the effects of patriarchal 'structures' on behavior of both women and men have moved from a family-based patriarchy to a stranger-based patriarchy. These many complex functional contexts provide us with questions and possibilities for now observing the functional contexts of modern western life, and for talking with participants about their 'mental health' behaviors and these functional contexts. The next step, therefore, is to participate in young people's lives and observe how these possible functional relationships actually play out in their real worlds, and what more complex strategies occur.

\section{Conclusions}

This paper has tried to show ways we can deal with the complex functional analyses and interventions required with complex human social behaviors. It was suggested that we need to expand behavior analysis with additional methods which describe the structuring of functional relations which already exists in our real lives. That is, unlike the experimenter with an animal chamber, we can neither set up nor control the contingent relations between humans in any meaningful or realistic way, and there are strong, already existing functional relations structured into our worlds. The functional relations are complex and often hidden from us, but they are structured into many contexts and form patterns that are repeated unless there is some explicit change. We can, therefore, still usefully describe or map (Guerin \& Guerin, 2008) the way those functional relations are structured, and even try changing them with the voluntary participation of the people involved.

This enterprise means we must analyze a wider range of contexts which shape human behavior, and just because they cannot be easily observed does not 
mean they do not have a strong functional influence. As I tried to show above, this even includes the economic contexts and the broad changes of modernity, which need to be part of the analyses and interventions with humans. Even when dealing with a single person behaving alone in their room, these societal patterns of functional relations are already part of the contexts for producing their 'solitary' behaviors (Guerin, 2001). This approach also means treating some standard 'functions' in new ways, such as the way food functions for social outcomes rather than feeding or appetitive outcomes (Guerin, 1992).

The same reasoning applies to intervention. To improve lives, and the example of mental health has been used in this paper because it is traditionally seen as having a very 'internal' origin, both small scale advocacy and large-scale societal changes are in fact part of any individual behavior change (cf. feminist therapy and Indigenous mental health interventions, Guerin, 2017b). Behavior and its functional outcomes are out there in the person's environment and world, so we need to use participatory, community-based research, but we need to do this with the functional focus of behavior analysis rather than just map out 'structures' and assume these determine human behavior in a 'causal' way (Guerin, 2010; Guerin \& Guerin, 2012). We need to 'get out into people's worlds' and spend more time finding out what is functional and shaping people's behaviors.

\section{References}

Baia, F. H., Neves, S. M. M., Almeida Filho, J. C. R., de Melo Junior, I. F., Souza, A. C. G., Lemes, I. G. (2017). Ethnogenesis of a Brazilian Indigenous community, a behavior analytic interpretation: Ethnogenesis of the Tapuios do Carretão. Behavior and Social Issues, 26, 51-66.

Braedley, S., \& Luxton, M. (2010). Neoliberalism and everyday life. Montreal: McGill-Queen's University Press.

de Carvalho, L, C., Sandaker, I., \& Ree, G. (2017). An ethnographic study of tagging cultures. Behavior and Social Issues, 26, 67-94.

Fromene, R. \& Guerin, B. (2014). Talking to Australian Indigenous clients with Borderline
Personality Disorder labels: Finding the context behind the diagnosis. The Psychological Record, 64, 569-579.

Fromene, R., Guerin, B., \& Krieg, A. (2014). Australian Indigenous clients with a Borderline Personality Disorder diagnosis: A contextual review of the literature. The Psychological Record, 64, 559-567.

Gibson, J. J. (1979). The ecological approach to visual perception. Boston: Houghton Mifflin

Giddens, A. (1990). The consequence of modernism. Oxford: Polity Press.

Goldiamond, I. (1975). Alternative sets as a framework for behavioral formulations and research. Behaviorism, 3, 49-85.

Guerin, B. (1992). Social behavior as discriminative stimulus and consequence in social anthropology. The Behavior Analyst, 15, 31-41.

Guerin, B. (1994). Analyzing social behavior: Behavior analysis and the social sciences. Reno, Nevada: Context Press.

Guerin, B. (1997). Social contexts for communication: Communicative power as past and present social consequences. In J. Owen (Ed.), Context and communication behavior (pp. 133-179). Reno, NV: Context Press.

Guerin, B. (2001). Individuals as social relationships: 18 ways that acting alone can be thought of as social behavior. Review of General Psychology, 5, 406-28.

Guerin, B. (2003). Language use as social strategy: A review and an analytic framework for the social sciences. Review of General Psychology, 7, 251-298.

Guerin, B. (2004). Handbook for analyzing the social strategies of everyday life. Reno, Nevada: Context Press.

Guerin, B. (2010). A framework for decolonization interventions: Broadening the focus for improving the health and wellbeing of Indigenous communities. Pimatisiwin: Indigenous and Aboriginal Community Health, 8, 61-83.

Guerin, B. (2016). How to rethink human behavior: A practical guide to social contextual analysis. London: Routledge.

Guerin, B. (2017a). How to rethink mental illness: The human contexts behind the labels. London: Routledge. 
Guerin, B. (2017b). Deconstructing psychological therapies as activities in context: What are the goals and what do therapists actually do? Revista Perspectivas em Análise do Comportamento, 8, 97-119.

Guerin, B., \& Guerin, P. B. (2008). Relationships in remote communities: Implications for living in remote Australia. The Australian Community Psychologist, 20, 74-86.

Guerin, B., \& Guerin, P. (2012). Re-thinking mental health for Indigenous Australian communities: Communities as context for mental health. Community Development Journal, 47 (4), 555570.

Guerin, B., Leugi, G. B., \& Thain, A. (2018). Attempting to overcome problems shared by both qualitative and quantitative methodologies: Two hybrid procedures to encourage diverse research. The Australian Community Psychologist, 29, 74-90.

Guerin, P. B., Elmi, F. H., \& Guerin, B. (2006). Weddings and parties: Cultural healing in one community of Somali women. The Australian e-Journal for the Advancement of Mental Health (AeJAMH), Vol. 5, Issue 2.

Harris, M. (1979). Cultural materialism: The struggle for a science of culture. NY: Random House.

Pe-Pua, R. (1989). Pagtatanong-tanong: A crosscultural research method. International Journal of Intercultural Relations, 13, 147 - 163.

Pomerantz, A. (1980). Telling my side: 'Limited access' as a 'fishing device.' Sociological Inquiry, 50, 186-198.

Rappaport, R. A. (1984). Pigs for the ancestors: Ritual in the ecology of a New Guinea people. London: Yale University Press.

Rowe, P., \& Guerin, B. (2018). Contextualizing the mental health of metal youth: A community for social protection, identity and musical empowerment. Journal of Community Psychology, 46, $1-13$.

Sidman, M. (1960). Tactics of scientific research: Evaluating experimental data in psychology. NY: Basic Books.

Skinner, B. F. (1938). The behavior of organisms. New York: Appleton-Century-Crofts.

Skinner, B. F. (1953). Science and human behavior. New York: The Free Press.
Skinner, B. F. (1957). Verbal behavior. Englewood Cliffs: Prentice Hall.

Trzepacz, D., Guerin, B., \& Thomas, J. (2014). Indigenous Country as a context for mental and physical health: Yarning with the Nukunu Community. The Australian Community Psychologist, 26, 38-53.

Willkinson, R., \& Pickett, K. (2010). The spirit level: Why greater equality makes societies stronger. NY: Bloomsbury Press.

\section{Informações do Artigo}

Histórico do artigo:

Submetido em: 23/08/2018

Primeira decisão editorial: 26/06/2019

Aceito em: 22/07/2019 